\title{
Estudo histomorfométrico da interface óssea do parafuso expansor cervical*
}

\author{
Histomorphometric analysis of bone-screw \\ interface of expansive cervical screw
}

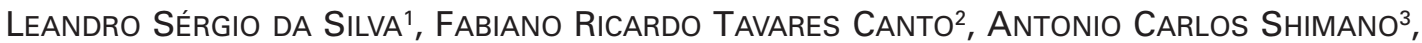 \\ Sergio Brito Garcia ${ }^{4}$, LUiz Antonio Salata ${ }^{5}$, Helton Defino 6
}

\section{RESUMO}

Objetivo: Realizar estudo experimental para a avaliação histomorfométrica da interface óssea dos parafusos expansores utilizados no sistema de fixação anterior da coluna cervical. Métodos: Foram utilizadas no estudo cinco vértebras cervicais de ovelhas

* Trabalho realizado no Laboratório de Bioengenharia do Departamento de Biomecânica, Medicina e Reabilitação do Aparelho Locomotor da Faculdade de Medicina de Ribeirão Preto da Universidade de São Paulo - USP - Ribeirão Preto (SP), Brasil.

1. Pós-graduando do Curso de Pós-Graduação da Área Ortopedia, Traumatologia e Reabilitação do Departamento de Biomecânica, Medicina e Reabilitação da Faculdade de Medicina de Ribeirão Preto da Universidade de São Paulo - USP - Ribeirão Preto (SP), Brasil.

2. Pós-graduando do Curso de Pós-Graduação da Área Ortopedia, Traumatologia e Reabilitação do Departamento de Biomecânica, Medicina e Reabilitação da Faculdade de Medicina de Ribeirão Preto da Universidade de São Paulo - USP - Ribeirão Preto (SP), Brasil.

3. Doutor, Professor do Departamento de Biomecânica, Medicina e Reabilitação da Faculdade de Medicina de Ribeirão Preto da Universidade de São Paulo - USP - Ribeirão Preto (SP), Brasil.

4. Professor Associado do Departamento de Patologia da Faculdade de Medicina de Ribeirão Preto da Universidade de São Paulo - USP - Ribeirão Preto (SP), Brasil.

5. Professor Associado do Departamentoto de Cirurgia e Traumatologia Buco-Maxilo-Facial e Periodontia(FORP) da Universidade de São Paulo - USP - Ribeirão Preto (SP), Brasil.

6. Professor Titular Departamento de Biomecânica, Medicina e Reabilitação da Faculdade de Medicina de Ribeirão Preto da Universidade de São Paulo - USP - Ribeirão Preto (SP), Brasil.

Endereço para correspondência: Av. Bandeirantes, 3.900, 11ㅇandar - Monte Alegre - 114048-900 - Ribeirão Preto (SP). Tel./fax: (16) 3633-0336. E-mail: hladefin@fmrp.usp.br

Recebido em 10/12/07. Aprovado para publicação em 12/2/08. Copyright RBO2008
(C4), nas quais os parafusos foram inseridos. $O$ parafuso expansor de $18,5 \mathrm{~mm}$ de comprimento e $5,0 \mathrm{~mm}$ de diâmetro externo (Ulrich) foi inserido em ambos os lados da véterbra $\mathrm{C} 4$. No lado esquerdo o parafuso era inserido sem o parafuso interno de expansão e, no lado direito, com o parafuso de expansão interna. $\mathrm{Na}$ porção inferior da vértebra foi confeccionado o orifício-piloto com broca de $2,5 \mathrm{~mm}$ sem a introdução de implante. A região da vértebra contendo os parafusos e o orifício-piloto foi preparada para estudo histológico da interface dos implantes e o tecido ósseo da parede do orifício-piloto. Por meio do estudo histomorfométrico foi avaliada a densidade óssea total, a densidade óssea externa (fora da rosca do parafuso), a densidade interna (dentro da rosca do parafuso) e a medida linear de contato entre o tecido ósseo e o implante. Resultados: A densidade óssea total foi maior no grupo I (parafuso expandido) em relação ao grupo III (controle). A densidade óssea externa foi maior nos grupos I (parafuso expandido) e II (não expandido) em relação ao grupo III. A densidade interna foi maior no grupo I em relação aos grupos II e III e maior no grupo II em relação ao grupo III. O contato linear foi maior no grupo I em relação aos grupos II e III. Conclusão: As alterações da estrutura do tecido ósseo ao redor dos parafusos expansores, detectadas imediatamente após a sua aplicação, forneceram subsídios para o entendimento da maior resistência ao arrancamento desses implantes, que poderiam estar relacionadas com a compactação do osso esponjoso ao redor do mesmo, proporcionando maior área de contato entre o implante e o tecido ósseo.

Descritores - Coluna vertebral/cirurgia; Fixação de fratura; 


\section{ABSTRACT}

Objective: To perform an experimental study for the Histomorphometric analysis of the bone interface of expansive screws used in the anterior cervical spine fixation system. Methods: Five sheep cervical vertebrae (C4) were used in the study, in which screws were inserted. The $18.5 \mathrm{~mm}$ long and $5.0 \mathrm{~mm}$ outer diameter expansive screws (Ulrich) were inserted in both sides of the C4 vertebra. On the left side, the screw was inserted without the internal expansive screw, which was used on the right side. A pilot hole was made on the lower portion of the vertebra with a $2.5 \mathrm{~mm}$ bore, but no implant was introduced. The vertebral region containing the screws and the pilot hole was prepared for a histological study of the interface between implants and bone screws, and of the pilot hole wall. Histomorphometric analysis evaluated total bone density, external bone density (outside the screw thread), internal density (inside the screw thread) and the linear measurement of the contact between bone tissue and the implant. Results: Total bone density was greater in group I (expansive screw) as compared to group III (control). External bone density was greater in groups I (expansive screw) and II (non-expansive screw) when compared to group III. Internal bone density was greater in group I when compared to groups II and III, and greater in group II when compared to group III. Linear contact was greater in group I when compared to groups II and III. Conclusion: structural changes around expansive screws detected immediately after their application provide subsidies for a better understanding of the greater tearing resistance of the implant, which could be related to the compacting of cancellous bone around the implant, while providing a larger contact area between the implant and the bone tissue.

Keywords - Spine/surgery; Fracture fixation; Bone screws; Cervical vertebrae; Sheep

\section{INTRODUÇÃO}

A fixação anterior da coluna vertebral por meio de placas teve seu inicio em 1967 com a utilização de placas não específicas para essa finalidade ${ }^{(1)}$. As placas em forma de " $\mathrm{H}$ " e especialmente desenhadas para a utilização na parte anterior das vértebras cervicais foram introduzidas por Orozco, em 1970, e foram a base para o desenvolvimento das gerações ulteriores de placas cervicais que seguiram o seu conceito e principio de fixação ${ }^{(2-10)}$.

Um dos problemas relacionados com a utilização das placas cervicais tem sido o afrouxamento e a soltura dos parafusos da placa, que podem resultar em perda da fixação e lesões do esôfago ${ }^{(11)}$. Uma das alternativas desenvolvidas para evitar a soltura dos parafusos utilizados na fixação das placas anteriores da coluna cervical foi o desenvolvimento dos parafusos expansores ${ }^{(12-13)}$. O diâmetro externo desses parafusos pode ser aumentado após sua introdução no interior da vértebra, aumentando sua resistência ao arrancamento e impedindo desse modo sua soltura e perda da fixação $0^{(12-13)}$.

O objetivo do trabalho foi estudar por meio do estudo histomorfométrico a interface entre o parafuso expansor e o tecido ósseo da vértebra cervical.

\section{MÉTODOS}

$\mathrm{Na}$ pesquisa foram utilizadas cinco ovelhas da raça Santa Inês com peso corporal médio de $32 \pm 4 \mathrm{~kg}$. A quarta vértebra cervical foi selecionada para a colocação dos implantes. A execução foi realizada no Laboratório de Bioengenharia do Departamento de Biomecânica, Medicina e Reabilitação do Aparelho Locomotor da Faculdade de Medicina de Ribeirão Preto USP.

Os animais foram submetidos a anestesia e a quarta vértebra cervical abordada por meio do acesso cirúrgico anterior da coluna cervical. Após a identificação e exposição da face anterior da quarta vértebra cervical foram realizadas três perfurações na vértebra utilizando broca de $2,5 \mathrm{~mm}$. Dois orifícios foram utilizados para a colocação dos parafusos (um parafuso com e outro sem o dispositivo expansor). Outro orifício foi utilizado como controle (figura 1).

Foram selecionados parafusos expansores do sistema de fixação cervical Ulrich. Os parafusos possuíam $18,5 \mathrm{~mm}$ de comprimento, diâmetro externo de $5 \mathrm{~mm}$ e diâmetro interno de $3,5 \mathrm{~mm}$. Um parafuso de menor diâmetro foi inserido no interior do corpo dos parafusos expansores e utilizado para aumentar seu diâmetro externo (figura 2). 


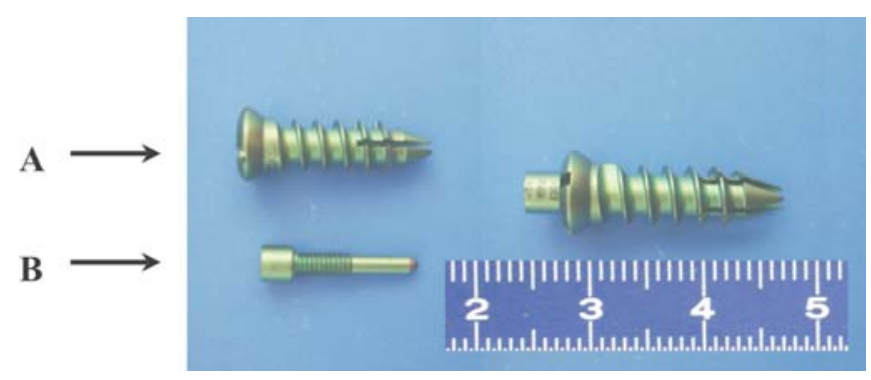

Figura 1 - Fotografia do parafuso expansor (A) e do dispositivo de expansão interna (B)

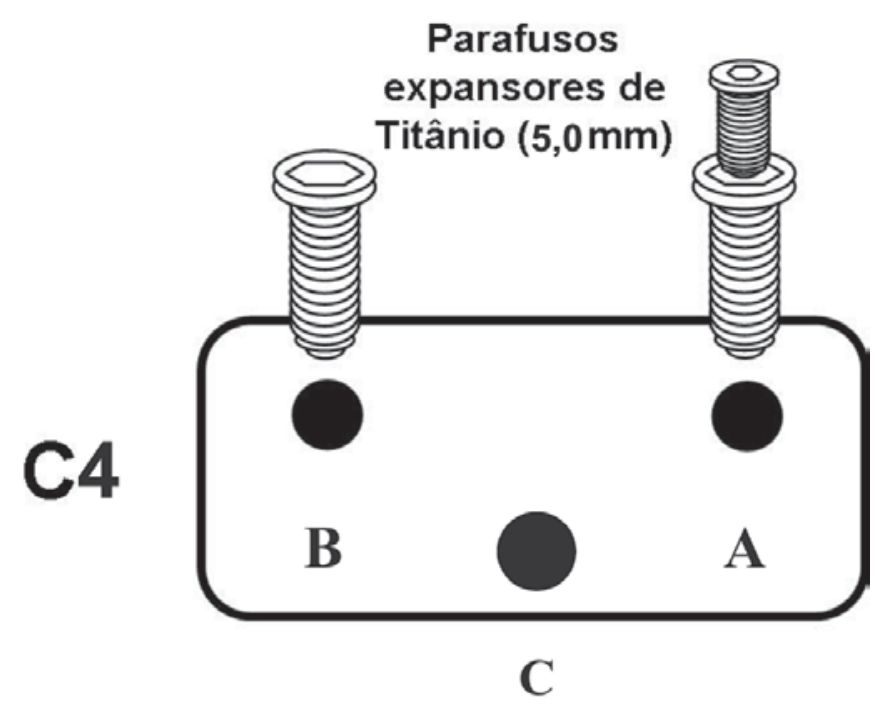

Figura 2 - Esquema da implantação dos parafusos. A) parafuso expandido; B) parafuso não expandido; e C) orifício-piloto.

Foram formados grupos experimentais de acordo com a utilização e colocação do parafuso interno: grupo I - parafuso expandido; grupo II - parafuso não expandido; e grupo III - controle.

Imediatamente após a colocação dos parafusos os animais eram sacrificados com dose letal de anestésico, segundo o recomendado por normas internacionais para pesquisa em animais, e o material preparado para o estudo histológico. O material foi incluído em resina de polimetilmetacrilato LR White ${ }^{\circledR}$ (London Resin Company, Berkshire, Inglaterra).

Foram realizados cortes no centro dos blocos no sentido longitudinal do orifício-piloto e do parafuso (figura 3). Os cortes foram preparados até atingir a espessura entre 10 e $30 \mu \mathrm{m}$. Para coloração utilizaram-se o azul de Stevenel e alizarina vermelha (figura 4).

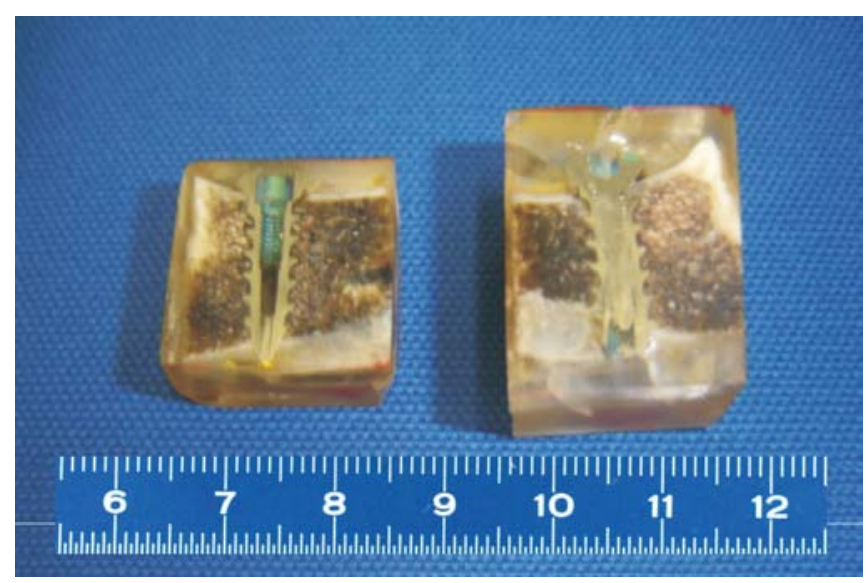

Figura 3 - Fotografia da vértebra após a sua inclusão na resina e secção. Observar os parafusos no seu interior.

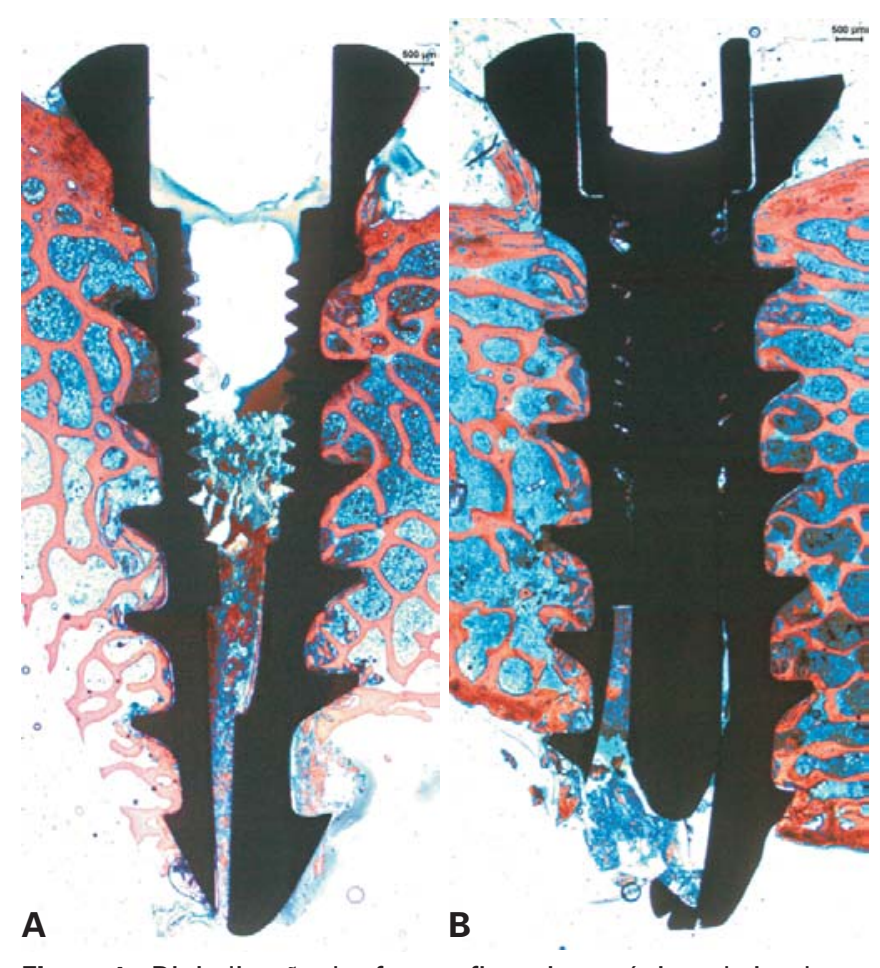

Figura 4 - Digitalização das fotografias microscópicas do implante não-expandido (A) e expandido (B). Aumento de 1,6x. Coloração: alizarina vermelha e azul de Stevenel.

Os parâmetros selecionados para a avaliação por meio do estudo histomorfométrico foram: o contato linear entre o osso e o implante, a densidade óssea total, a densidade óssea externa (fora da rosca do parafuso) e a densidade óssea interna (dentro da rosca do parafuso) (figura 5). 

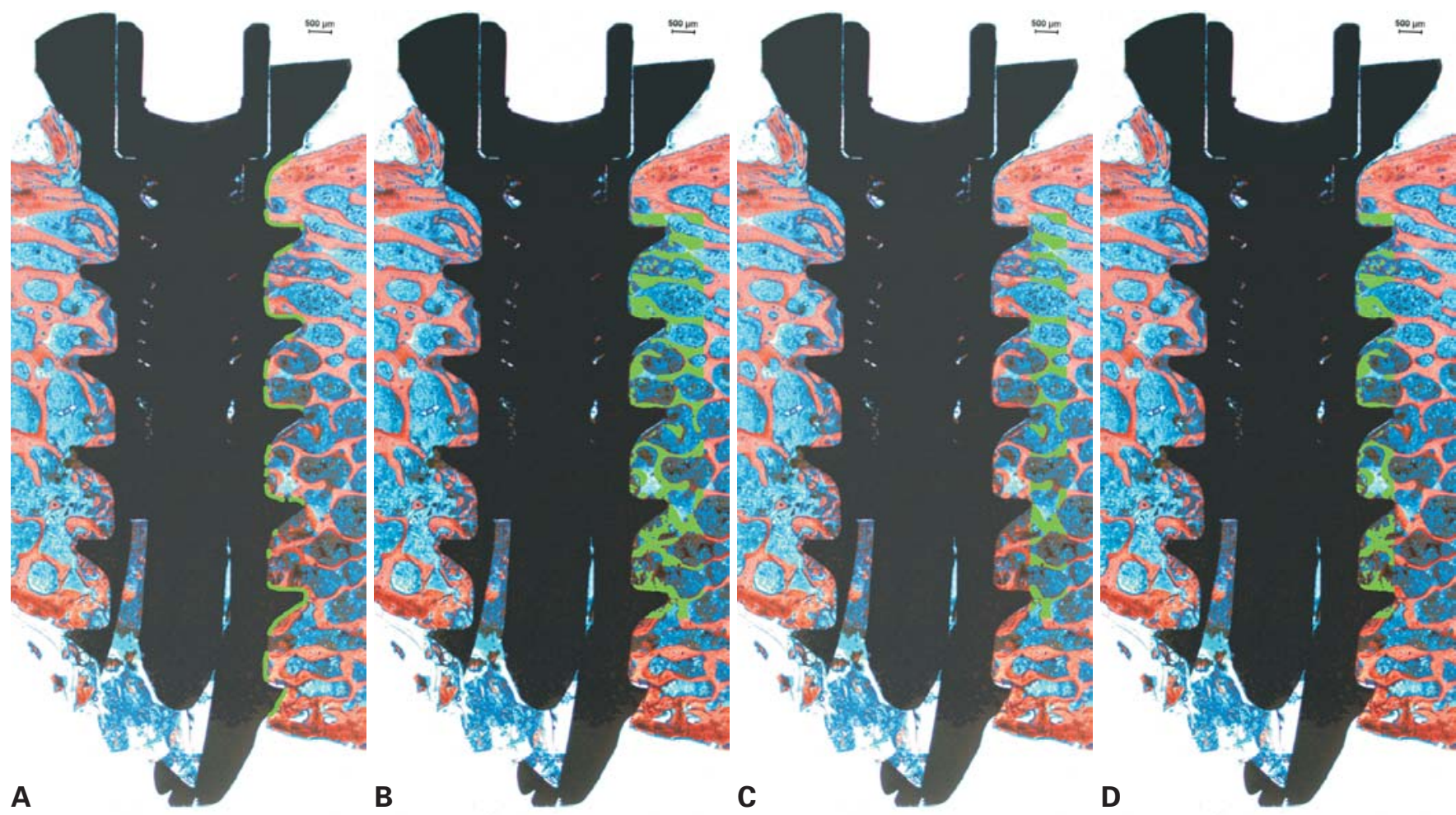

Figura 5 - Fotomicrografia ilustrando (em verde) os parâmetros avaliados por meio da histomorfometria. A) contato linear entre o implante e o osso. B) densidade óssea total. C) densidade óssea externa (fora da rosca do parafuso) e D) densidade óssea interna (dentro da rosca do parafuso). (Coloração com alizarina vermelha e azul de Stevenel). Aumento de 1,6x.

As imagens fotomicrográficas (figura 4) foram captadas no equipamento da marca Leica ${ }^{\circledR}$ (Leica Microsystems GmbH Nussloch, Alemanha), que era composto de câmera digital especial para microfotografia, acoplada ao microscópio conectado ao microcomputador previamente calibrado para as análises histomorfométricas. Para a análise das imagens foram utilizados dois programas específicos: o UTHSCSA Image Tool (Versão 3.0), para obter as medidas lineares de contato ossoimplante, e o Leica Quiuin ${ }^{\circledR}$ (Leica Microsystems GmbH Nussloch, Alemanha), para a determinação da medida das áreas, que foram transformadas em densidade óssea (densidade óssea total, interna e externa).

Os dados foram analisados por um examinador independente que não tinha conhecimento do grupo experimental a que pertencia cada amostra.

A análise estatística foi realizada por meio do teste de normalidade (Kolmogorov-Smirnov). Para a análise simultânea dos grupos, foi utilizado o teste ANOVA (One Way Analysis of Variance) para dados paramétri- cos e, para a comparação entre os grupos experimentais, o teste de Tukey-Kramer (Tukey's Multiple Comparison Test) por meio do programa Grafhpad Prism ${ }^{\circledR}$ v.4.03. Todas as análises foram feitas com nível de significância de $5 \%$.

\section{RESULTADOS}

As características dos cortes histológicos dos parafusos expandidos, não expandidos e do controle (orifício-piloto) podem ser observadas na figura 6 .

Nos implantes do grupo I (parafuso expandido) a média da medida linear de contato osso-implante foi de 12,58 $\pm 2,30 \mathrm{~mm}$; no grupo II (parafuso não expandido), de 9,51 $\pm 1,36 \mathrm{~mm}$; e no grupo III (controle), de $8,21 \pm 0,86 \mathrm{~mm}$. Os dados da medida linear de contato osso-implante foram submetidos ao teste de Kolmogorov-Smirnov e apresentaram distribuição normal, sendo assim submetidos à análise estatística paramétrica. $\mathrm{Na}$ análise simultânea dos grupos experimentais foram detectadas diferenças estatísticas (ANOVA $-\mathrm{p}<$ 

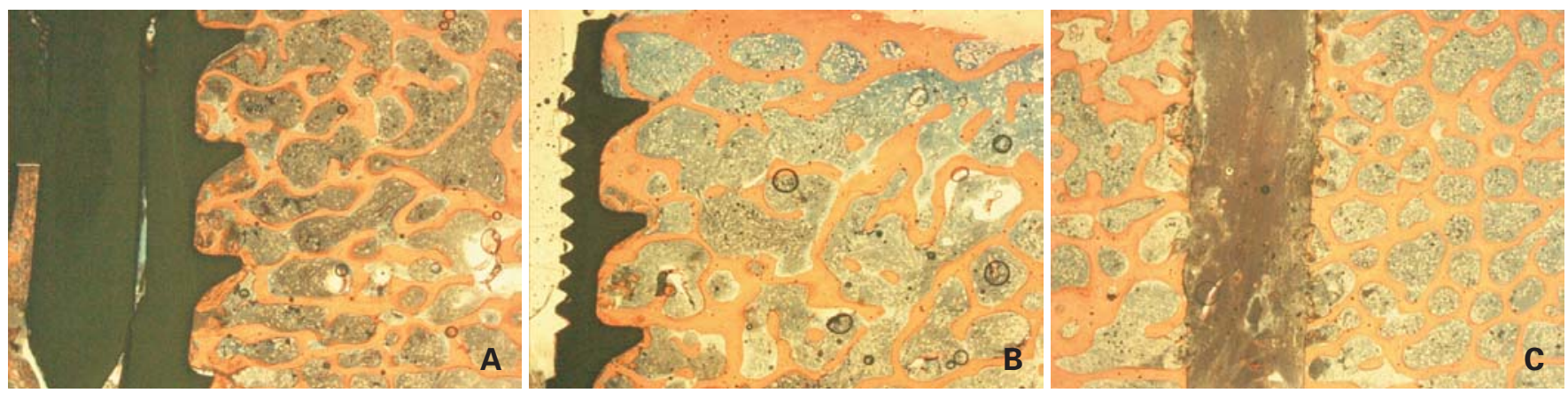

Figura 6 - Fotografias histológicas demonstrando: parafuso expandido (A); parafuso não-expandido (B); controle (C). (Alizarina vermelha e azul de Stevenel. Aumento de 1,6x).

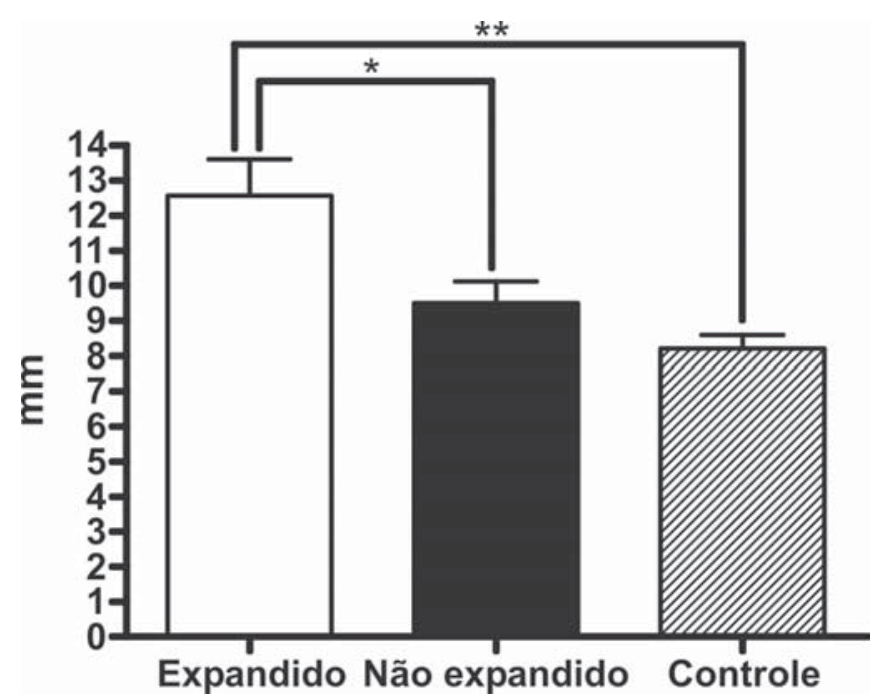

Figura 7 - Gráfico ilustrando a comparação entre os valores da medida linear de contato osso-implante. Os asteriscos $\left({ }^{*} \mathrm{e}^{* *}\right)$ indicam diferença estatística entre os grupos experimentais.

0,05). Na comparação entre os grupos (Tukey's Multiple Comparison Test), foi observada diferença estatística entre o grupo I e o grupo III $(\mathrm{p}<0,01)$, e entre o grupo I e o grupo II $(\mathrm{p}<0,05)$ (figura 7$)$.

Nos implantes do grupo I a média da densidade óssea total foi de $0,39 \pm 0,11$; no grupo II, de $0,33 \pm$ 0,05 ; e de $0,21 \pm 0,00$ no grupo III. Foi observada diferença estatística entre os grupos I e III $(\mathrm{p}<0,05)$ (figura 8).

A densidade óssea externa (fora da rosca do implante) foi de 0,18 $\pm 0,02$ no grupo I, de 0,20 $\pm 0,01$ no grupo II e de $0,14 \pm 0,01$ no grupo III. Foi observada diferença estatística entre os grupos I e III $(\mathrm{p}<0,01)$ e entre os grupos II e III $(\mathrm{p}<0,001)$ (figura 9).

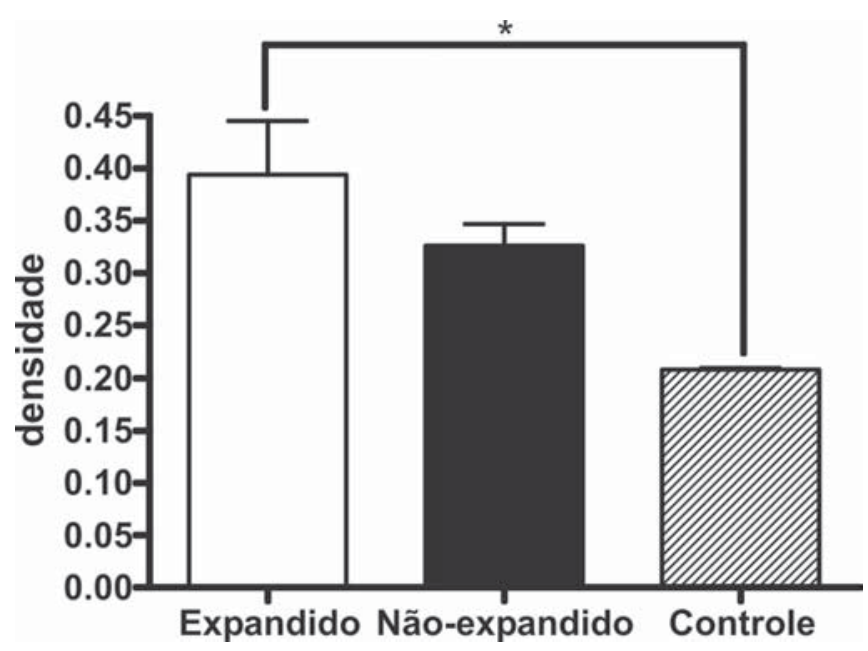

Figura 8 - Gráfico ilustrando a comparação da densidade óssea total entre os grupos experimentais. O asterisco $\left(^{*}\right)$ indica diferença estatística entre os grupos.

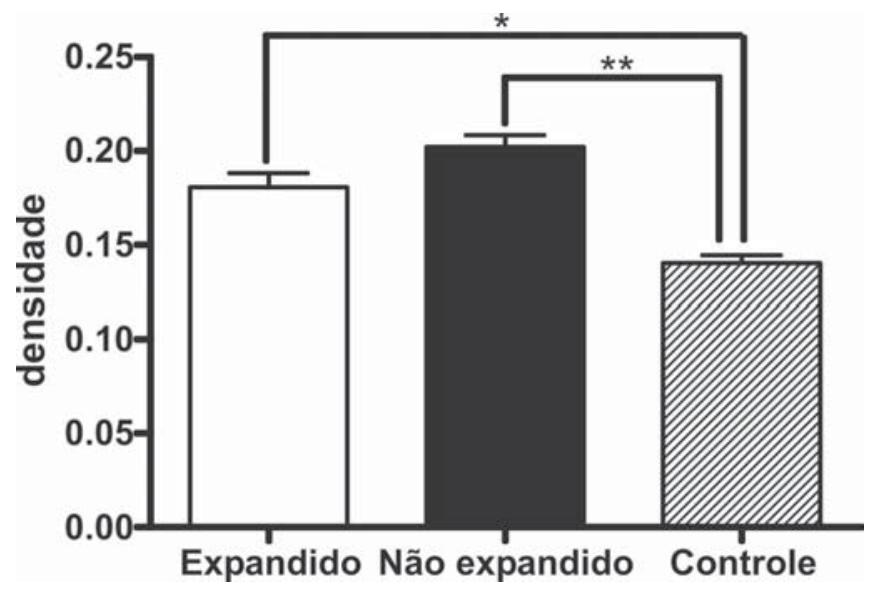

Figura 9 - Gráfico ilustrando a comparação da densidade óssea fora das roscas dos parafusos. Os asteriscos $\left(* e^{* *}\right)$ indicam diferença estatística entre os grupos experimentais. 
A densidade óssea interna (dentro da rosca do parafuso) foi de 0,18 $\pm 0,02$ no grupo I, de 0,20 $\pm 0,01$ no grupo II e de 0,14 $\pm 0,01$ no grupo III. Foi observada diferença estatística entre os grupos I e III $(\mathrm{p}<0,01)$ e entre os grupos I e II $(\mathrm{p}<0,05)$ (figura 10$)$.

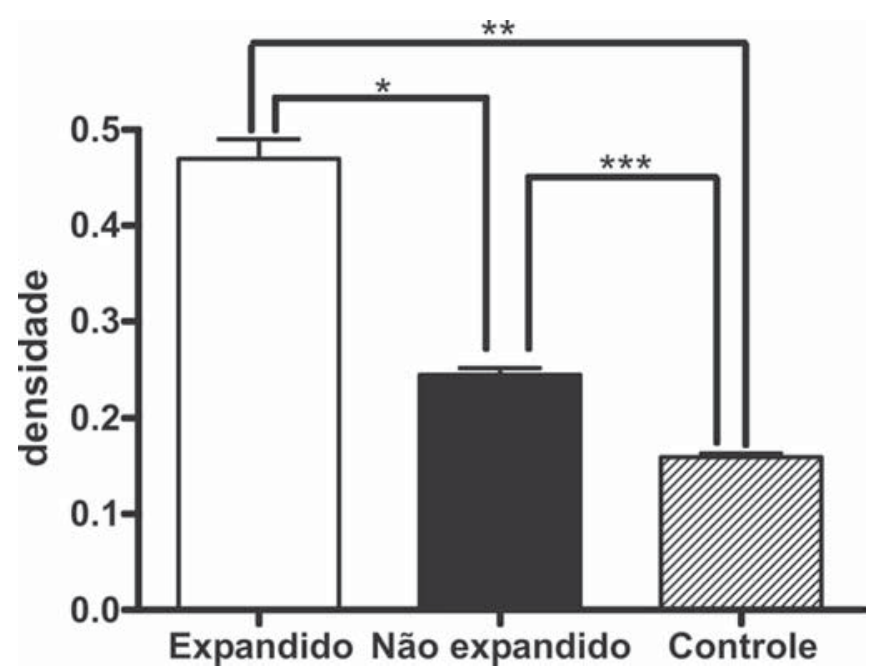

Figura 10 - Gráfico ilustrando a comparação dos valores da densidade óssea dentro das roscas dos implantes. Os asteriscos $\left(^{*}\right.$, ${ }^{*} e^{* * *}$ ) indicam diferença estatística entre os grupos experimentais.

\section{DISCUSSÃO}

A soltura dos parafusos utilizados para a fixação das placas cervicais anteriores tem sido observada desde o desenvolvimento dessa modalidade de tipo de fixação. A soltura dos parafusos ocorria em maior escala nas placas de fixação que utilizavam somente um parafuso em cada vértebra comparado com as placas que permitem a utilização de dois parafusos em cada vértebra $^{(11)}$. A percentagem da soltura dos parafusos nas diferentes séries clínicas tem sido ao redor de $3 \%$ e esse fato tem motivado a procura de soluções para contornar esse problema ${ }^{(3-5-11)}$. A ancoragem dos parafusos na parede posterior da vértebra era preconizada nos sistemas mais antigos de fixação da coluna cervical. A expansão dos parafusos foi uma das alternativas apresentadas para evitar a soltura, tendo sido empregados parafusos expansíveis pela introdução de outro no seu interior. Duas modalidades de expansão foram desenvolvidas com a utilização desse conceito: a ex- pansão da cabeça do parafuso (parte proximal) sobre o orifício da placa e a expansão da parte distal ou corpo do parafuso sobre o tecido ósseo adjacente ${ }^{(3,5-11)}$.

A expansão do corpo do parafuso no interior da vértebra provoca alterações imediatas da estrutura óssea adjacente e essas alterações foram o alvo do estudo que realizamos.

De acordo com os parâmetros analisados neste estudo, ocorreu maior contato da superfície dos parafusos expandidos com o tecido ósseo e a densidade óssea no interior das trabéculas ósseas foi maior no grupo do parafuso expandido. Esses resultados, em acordo com a literatura, refletem a compressão do tecido ósseo produzida pela expansão do parafuso, que teoricamente realizaria a compactação do osso esponjoso ao seu redor, aumentado desse modo a resistência ao arrancamento desses implantes, o que tem sido demonstrado nos ensaios mecânicos ${ }^{(12-14)}$. Esse aumento da resistência ao arrancamento desses implantes poderia também ser provocado pelo aumento do diâmetro externo do implante, que influenciaria na resistência ao arrancamento $^{(12-14)}$.

Observamos que a expansão do parafuso não produziu alterações na estrutura óssea fora da área do contato das roscas; isso demonstra que sua expansão não causa danos ao tecido ósseo fora da área das roscas do parafuso. O efeito da compactação do tecido ósseo adjacente ao corpo do parafuso, provocado pela perfuração do orifício-piloto de diâmetro menor que a alma do parafuso, pode ser observado no grupo em que os parafusos foram ou não expandidos, quando comparados com o orifício-piloto. No entanto, na área fora do limite da rosca dos parafusos as alterações foram semelhantes entre os parafusos expandidos e não expandidos.

O estudo da interface entre os parafusos utilizados na coluna vertebral e o osso da vértebra não tem sido realizado com frequiência e não encontramos estudos semelhantes para fazer a comparação dos resultados. Os estudos têm sido limitados às características biomecânicas dos parafusos expansores ${ }^{(13)}$.

Nossos resultados mostraram que o parafuso expansor permitiu maior compactação do tecido ósseo adjacente ao implante, promovendo aumento da densida- 
de óssea ao redor do mesmo. As variáveis estudadas apresentaram, de modo geral, maiores valores no grupo em que os parafusos foram expandidos. No entanto, essas alterações são imediatas e devem ser também analisadas considerando a reação do tecido ósseo e as alterações que podem ocorrer com a sua remodelação e reação aos microtraumatismos após a colocação dos parafusos no interior da vértebra.

\section{CONCLUSÕES}

As alterações da estrutura do tecido ósseo ao redor dos parafusos expansores, detectadas imediatamente após a sua aplicação, forneceram subsídios para o entendimento da maior resistência ao arrancamento desses implantes, que poderiam estar relacionadas com a compactação do osso esponjoso ao redor do mesmo, proporcionando maior área de contato entre o implante e o tecido ósseo.

\section{REFERENCIAS}

1. Böhler J. Sofort- und Frühbehandlung traumatischer Querschnittslähmungen. Z Orthop Ihre Grenzgeb. 1967; 103(4):512-29.

2. Orozco-Declos R, Llovet-Tapies J. Osteosintesis en las fracturas del raquis cervical: nota técnica. Rev Ortop Traumatol. 1970;14:285-8.

3. Bose B. Anterior cervical arthrodesis using DOC dynamic stabilization implant for improvement in sagittal angulation and controlled settling. J Neurosurg. 2003;98(1 Suppl):8-13.

4. Brodke DS, Klimo P Jr, Bachus KN, Braun JT, Dailey AT. Anterior cervical fixation: analysis of load-sharing and stability with use of static and dynamic plates. J Bone Joint Surg Am. 2006;88(7):1566-73.
5. Connolly PJ, Esses SI, Kostuik JP. Anterior cervical fusion: outcome analysis of patients fused with and without anterior cervical plates. J Spinal Disord. 1996;9(3):202-6.

6. Gassman J, Seligson D. The anterior cervical plate. Spine. 1983;8(7):700-7.

7. Majd ME, Vadhva M, Holt RT. Anterior cervical reconstruction using titanium cages with anterior plating. Spine. 1999;24(15): 1604-10.

8. Pitzen T, Lane C, Goertzen D, Dvorak M, Fisher C, Barbier D, et al. Anterior cervical plate fixation: biomechanical effectiveness as a function of posterior element injury. J Neurosurg. 2003;99(1 Suppl):84-90.

9. Franco JS, Oliveira RP, Cristante AF, Leivas TP, Marcon RM, Barbarini AF, Barros Filho TEP. Estudo experimental da resistência das osteossínteses com placas e parafusos na fixação anterior da coluna cervical. Acta Ortop Bras. 2007;15(4):191-6.

10. Santos RT, Tisot OF, Oliveira LFM, Tisot RA, Fuzer J. Luxações da coluna cervical uni e bifacetárias: avaliação epidemiológica e tratamento. Coluna/Columna. 2006;5(4):222-8.

11. Weidner A. Internal fixation with metal plates and screws. In: Sherk H, editor. The cervical spine. 2nd ed. Philadelphia: JB Lippincott; 1989. p.404-21.

12. Cook SD, Salkeld SL, Whitecloud TS 3rd, Barbera J. Biomechanical evaluation and preliminary clinical experience with an expansive pedicle screw design. J Spinal Disord. 2000; 13(3):230-6.

13. Lesoin F, Jomin M, Viaud C. Expanding bolt for anterior cervical spine osteosynthesis: technical note. Neurosurgery. 1983;12(4):458-9.

14. Richter M, Wilke HJ, Kluger P, Claes L, Puhl W. Biomechanical evaluation of a newly developed monocortical expansion screw for use in anterior internal fixation of the cervical spine. In vitro comparison with two established internal fixation systems. Spine. 1999;24(3):207-12. 